\title{
Predictors of Chemotherapy Induced Adverse Events in Pediatric Osteosarcoma Patients
}

\author{
Phitjira Sanguanboonyaphong ${ }^{1,2}$, Patcharee Komvilaisak ${ }^{3}$, Kunanya \\ Suwannaying ${ }^{3}$, Jukapun Yoodee ${ }^{2,4}$, Manit Saeteaw ${ }^{1}$, Suthan Chanthawong ${ }^{5}$, \\ Suphat Subongkot ${ }^{5 *}$
}

\begin{abstract}
Objective: To investigate the prevalence of chemotherapy-induced adverse events and the associated risk factors in pediatric patients with osteosarcoma. Methods: This retrospective cross-sectional study enrolled 90 pediatric osteosarcoma patients (with 1,017 chemotherapy cycles) treated at Srinagarind Medical Center, Faculty of Medicine, Khon Kaen University, Khon Kaen, Thailand, between January 1, 2008 and December 31, 2018. The prevalence of major adverse events and a correlation between baseline characteristics and adverse events were analyzed using a generalized estimating equation model. Result: The prevalence of adverse events in 90 pediatric osteosarcoma patients (with 1,017 chemotherapy cycles) was determined as chemotherapy-induced nausea and vomiting $(29.2 \% ; n=296)$, hepatotoxicity $(21.2 \% ; n=215)$, anemia $(70.69 \% ; n=719)$, neutropenia $(26.65 \% ; n=271)$, and thrombocytopenia $(13.65 \% ; n=139)$. Factors associated with chemotherapy-induced hepatotoxicity included methotrexate dose $\geq 12 \mathrm{~g} / \mathrm{m} 2$ (odds ratio [OR] $1.30 ; 95 \%$ confidence interval $[\mathrm{CI}] 1.22-1.39 ; \mathrm{P}<0.001)$, plasma concentration of methotrexate at 72 hours $>0.1 \mu \mathrm{M}$ (OR 1.22; 95\% CI 1.19-1.25; $\mathrm{P}<0.001)$, and pre-hydration rate $\leq 125 \mathrm{~mL} / \mathrm{m}^{2} / \mathrm{h}(\mathrm{OR} 1.10 ; 95 \%$ CI 1.07-1.12; $\mathrm{P}<0.001)$. Conclusion: Major adverse events are becoming more common in pediatric osteosarcoma patients, and risk factors include larger chemotherapy doses, higher plasma methotrexate concentrations, and a slower pre-hydration rate. The outcomes of the study could aid in the better treatment of toxicity in children with osteosarcoma.
\end{abstract}

Keywords: Osteosarcoma-adverse events- chemotherapy

Asian Pac J Cancer Prev, 23 (1), 93-100

\section{Introduction}

Osteosarcoma is a common primary bone tumor of childhood and primarily located in the metaphysis of long bones (Jackson et al., 2016; Noah et al., 2016; Ksontini et al., 2018). It is ranked as the tenth most common pediatric malignancy in Thailand (Wiangon et al, 2011). The age-standardized incidence of osteosarcoma in individuals younger than 20 years is 3.1 per million per year (Wiangon et al, 2011), with a 5-year survival rate of $33.7 \%$ (Wiangon et al, 2011). Typically, 10\% to $20 \%$ of patients have metastases at the time of diagnosis (Gianferante et al., 2017; Misaghi et al., 2018). A high burden of disease increases morbidity and mortality, compromising survival ability of affected patients (Misaghi et al., 2018). A multimodal treatment combining surgery and chemotherapy has been reported to increase a 5-year survival rate from $20 \%$ to $60 \%$ in patients with osteosarcoma (Jain and Kapoor, 2016).
Still, using combination treatment resulted in major adverse events (AE), such as gastrointestinal (GI) toxicities including chemotherapy-induced nausea and vomiting (CINV), mucositis, diarrhea, and hematologic toxicities, such as anemia, neutropenia, and thrombocytopenia (Janeway and Grier, 2010). A previous report evaluating a burden of adverse health outcomes demonstrated that $64 \%$ of pediatric osteosarcoma patients experienced a high or severe burden of AE particularly GI toxicity and nephrotoxicity (Geenen et al., 2007).

Considering factors associating with $\mathrm{AE}$ following osteosarcoma treatment, high- dose chemotherapy and intravenous (IV) hydration rate during high dose methotrexate (HD-MTX) were often described. Since the adverse events from pediatric osteosarcoma treatment are frequent, yet very few systematic AE reports among pediatric osteosarcoma patients are available. Therefore, we aimed to study the prevalence and risk factors associated with treatment-related AE in pediatric patients

${ }^{1}$ Faculty of Pharmaceutical Sciences, Ubon Ratchathani University, Ubon Ratchathani 34190, Thailand. ${ }^{2}$ The College of Pharmacotherapy of Thailand, Nonthaburi 11000, Thailand. ${ }^{3}$ Faculty of Medicine, Khon Kaen University, Khon Kaen 40002, Thailand. ${ }^{4}$ Faculty of Pharmacy, Chiang Mai University, Chiang Mai 50200, Thailand. ${ }^{5}$ Faculty of Pharmaceutical Sciences, Khon Kaen University, Khon Kaen 40002, Thailand. FFor Correspondence: supsub2@kku.ac.th 
with osteosarcoma.

\section{Materials and Methods}

This retrospective cross-sectional study was conducted by reviewing the electronic medical records (EMRs) of 90 pediatric patients who received chemotherapy for osteosarcoma at the Department of Pediatrics, Srinagarind Medical Center, Faculty of Medicine, Khon Kaen University, Khon Kaen, Thailand, between January $1^{\text {st }}$, 2008-December $31^{\text {st }}, 2018$. The study was approved by the Center for Ethics in Human Research, Khon Kaen University, Khon Kaen, Thailand (HE621309).

The inclusion criteria included patients aged less than 18 years with a histologically proven diagnosis of osteosarcoma, and receiving IV chemotherapy during hospitalization. Patients without records of MTX plasma concentration, AE outcome and AE management were excluded.

\section{Chemotherapy regimen and IV hydration strategy}

Pediatric patients with osteosarcoma were treated according to Thai Pediatric Oncology Group (TPOG) protocol (Thai Pediatric Oncology Group, 2016), which constitutes of neoadjuvant chemotherapy starting 10 to 14 weeks before surgery and adjuvant chemotherapy starting 1 to 3 weeks after surgery and continuing for 9 to 10 weeks. During the neoadjuvant phase, all patients received the MAP regimen (doxorubicin $37.5 \mathrm{mg} / \mathrm{m}^{2} /$ day IV bolus for 2 days, cisplatin $60 \mathrm{mg} / \mathrm{m}^{2} /$ day IV administered over 6 hours for 2 days every 2 weeks, HD-MTX $12 \mathrm{~g} / \mathrm{m}^{2} /$ day IV administered over 4 hours, and leucovorin 15 $\mathrm{mg} / \mathrm{m}^{2} /$ dose IV administered over 2 hours every 6 hours and started 24 hours after completing the MTX infusion to be given as a 2-weeks-on and 1-week-off therapy per treatment cycle). Subsequently, adjuvant chemotherapy was administered according to response criteria (Hanafy et al., 2018). For patients with good response ( $>90 \%$ tumor necrosis), the MAP regimen was continued. For those with a poor response demonstrating less than or equal to $90 \%$ tumor necrosis, the MAPI regimen would have been selected, with the addition of ifosfamide $2.4 \mathrm{~g} / \mathrm{m}^{2} /$ day IV administered over 1 hour once daily for 5 days, every 3 weeks, together with mesna $600 \mathrm{mg} / \mathrm{m}^{2} /$ dose IV, given at $0,3,6$, and 9 hours following ifosfamide administration.

In Addition, IV crystalloid fluid hydration was administered at a rate of 125 to $200 \mathrm{~mL} / \mathrm{m}^{2} / \mathrm{h}$ at the physician's discretion. Sodium bicarbonate (40-60 $\mathrm{mEq} / \mathrm{L}$ ) was subsequently administered at least 12 hours before the MTX infusion to maintain a urinary $\mathrm{pH}$ of 7 or higher. Medications interfering with MTX clearance, such as nonsteroidal anti-inflammatory drugs (NSAIDs), cotrimoxazole, proton-pump inhibitors, and aspirin were suspended for up to 72 hours following MTX therapy.

\section{Chemotherapy-induced $A E$}

AEs (nausea, vomiting, mucositis, hepatotoxicity, nephrotoxicity, neurotoxicity, and bone marrow suppression) were retrospectively reviewed in all patients during and after each course of chemotherapy. AEs were confirmed by two pediatric oncologists based on clinical manifestations and laboratory value available in the patient medication records and EMRs. All AE were assessed through Naranjo's algorithm, whereby a score greater than or equal to 5 means a probability of inclusion in the study (Naranjo et al., 1981). The severity of all AE was graded by using the Common Terminology Criteria for Adverse Events (CTCAE) version 5 (Constable et al., 2019). Rare AE (i.e., Fanconi's syndrome and encephalopathy) were confirmed by physicians based on computed tomography (CT) scanning and other relevant techniques.

\section{Endpoints}

The primary endpoint was the prevalence of chemotherapy-induced AE during the treatment of pediatric osteosarcoma. The secondary endpoint was the risk factor associated with chemotherapy-induced AE.

\section{Statistical analysis}

The baseline characteristics were analyzed using descriptive statistics. The prevalence of AE was reported in terms of frequency and percentage. The correlation between risk factors and AE was analyzed using the generalized estimating equation (GEE) model. A sample size of 86 patients was required to achieve $80 \%$ power to detect a 10\% prevalence of AE (Traivaree et al., 2018). Statistical significance was based on the two-sided test with $\mathrm{P}<0.05$. STATA version 16 (StataCorp LP, College Station, TX, USA) was used for statistical analyses and data management.

\section{Results}

Ninety pediatric patients with osteosarcoma who were treated during the study period were included and 1,017 chemotherapy cycles were reviewed. The majority of patients were female $(52.22 \%)$, and the median age at diagnosis was $11.18 \pm 2.69$ years; and $53 \%$ had metastatic disease at diagnosis and lung was the most extensive site of distant metastasis (43.33\%). The most common subtype of osteosarcoma was the osteoblastic type (73.33\%), and the distal femur was the most frequent tumor location (43.33\%). All baseline demographic data are shown in Table 1.

AEs reports included GI toxicities, hematologic toxicities, nephrotoxicity, and neurotoxicity. The most frequent adverse event was anemia $(70.69 \%)$. The other hematologic toxicities included neutropenia, febrile neutropenia, and thrombocytopenia (prevalence of $20.69 \%, 1.73 \%$, and $13.65 \%$, respectively). Grade 2 severity anemia and neutropenia were observed in $34.32 \%$ and $10.13 \%$ of the patients, respectively. The severity of thrombocytopenia was only seen in Grade $1(7.76 \%)$. The prevalence of CINV was $29.2 \%$, of which the majority were grade 3 to 4 severity $(15.90 \%)$. The prevalence of hepatotoxicity was $21.2 \%$, of which the majority was grade 3 in severity $(8.67 \%)$. The most common nephrotoxicity included acute kidney injury $(1.37 \%)$ and electrolyte imbalance (1.67\%). The prevalence and severity grading of all other AE are shown in Table 2.

Even though it is rarely reported, a Fanconi's syndrome was identified in a 12-year-old girl with osteosarcoma 
DOI: 10.31557/APJCP.2022.23.1.93

Predictors of Chemotherapy Induced Adverse Events in Pediatric Osteosarcoma Patients

Table 1. Baseline Characteristics

\begin{tabular}{|c|c|}
\hline Characteristics & No. $(n=90)(\%)$ \\
\hline \multicolumn{2}{|l|}{ Sex } \\
\hline Male & $43(47.78)$ \\
\hline Female & $47(52.22)$ \\
\hline Age at diagnosis median $+/-$ IQR & $11.18 \pm 2.69$ \\
\hline \multicolumn{2}{|l|}{ Age group, years } \\
\hline $0-5$ & $2(2.22)$ \\
\hline $6-10$ & $26(28.89)$ \\
\hline $11-15$ & $62(68.89)$ \\
\hline \multicolumn{2}{|l|}{ BMI (age percentile) } \\
\hline Underweight & $23(25.56)$ \\
\hline Normal & $49(54.44)$ \\
\hline Overweight & $8(8.89)$ \\
\hline Obesity & $10(11.11)$ \\
\hline \multicolumn{2}{|l|}{ Osteosarcoma } \\
\hline Conventional type* & $84(93.33)$ \\
\hline Telangiectatic type & $4(4.44)$ \\
\hline Chondromyxoid fibroma & $1(1.11)$ \\
\hline Small cell osteosarcoma & $1(1.11)$ \\
\hline \multicolumn{2}{|l|}{ Tumor site } \\
\hline Distal femur & $40(44.44)$ \\
\hline Proximal tibia & $22(24.44)$ \\
\hline Proximal humerus & $10(11.11)$ \\
\hline Distal tibia & $7(7.78)$ \\
\hline Proximal femur & $5(5.56)$ \\
\hline Maxilla & $4(4.44)$ \\
\hline Fibula & $1(1.11)$ \\
\hline Sphenoid bone & $1(1.11)$ \\
\hline
\end{tabular}

BMI, body mass index; *Conventional type consists of osteoblastic, chondroblastic, and fibroblastic subtypes
Table 2. Prevalence and Severity of Adverse Events

\begin{tabular}{lll}
\hline Events (N=1,017) & No. $(\%)$ & $95 \%$ CI \\
\hline $\begin{array}{l}\text { Chemotherapy-induced nausea and } \\
\text { vomiting }\end{array}$ & $296(29.10)$ & $0.26-0.32$ \\
Grade 1-2 & $134(13.20)$ & $0.11-0.15$ \\
Grade 3-4 & $162(15.90)$ & $0.13-0.18$ \\
Mucositis & $69(6.79)$ & $0.05-0.08$ \\
Grade 1-2 & $31(3.05)$ & $0.02-0.04$ \\
Grade 3-4 & $38(3.74)$ & $0.02-0.05$ \\
Hepatotoxicity & $215(21.19)$ & $0.18-0.24$ \\
Grade 1-2 & $104(10.25)$ & $0.08-0.12$ \\
Grade 3-4 & $111(10.94)$ & $0.09-0.13$ \\
Anemia & $719(70.79)$ & $0.67-0.73$ \\
Grade 1-2 & $602(59.19)$ & $0.56-0.62$ \\
Grade 3-4 & $118(11.60)$ & $0.09-0.14$ \\
Neutropenia & $271(26.55)$ & $0.24-0.29$ \\
Grade 1-2 & $109(10.72)$ & $0.08-0.13$ \\
Grade 3-4 & $161(15.83)$ & $0.14-0.18$ \\
Thrombocytopenia & $139(13.65)$ & $0.12-0.16$ \\
Grade 1-2 & $93(9.13)$ & $0.07-0.11$ \\
Grade 3-4 & $46(4.52)$ & $0.03-0.05$ \\
\hline CI
\end{tabular}

CI, confidence interval

undergoing ifosfamide $2.4 \mathrm{~g} / \mathrm{m}^{2}$ IV for five consecutive days. The laboratory results revealed abnormal blood

\begin{tabular}{lccc}
\hline Events (N=1,017) & Total AE & Gr 1-2 & Gr 3-4 \\
\hline CINV & 29.1 & 13.2 & 15.9 \\
Mucositis & 6.79 & 3.05 & 3.74 \\
Hepatotoxicity & 21.19 & 10.25 & 10.94 \\
Anemia & 70.79 & 59.19 & 11.6 \\
Neutropenia & 26.55 & 10.72 & 15.83 \\
Thrombocytopenia & 13.65 & 9.13 & 4.52 \\
\hline
\end{tabular}

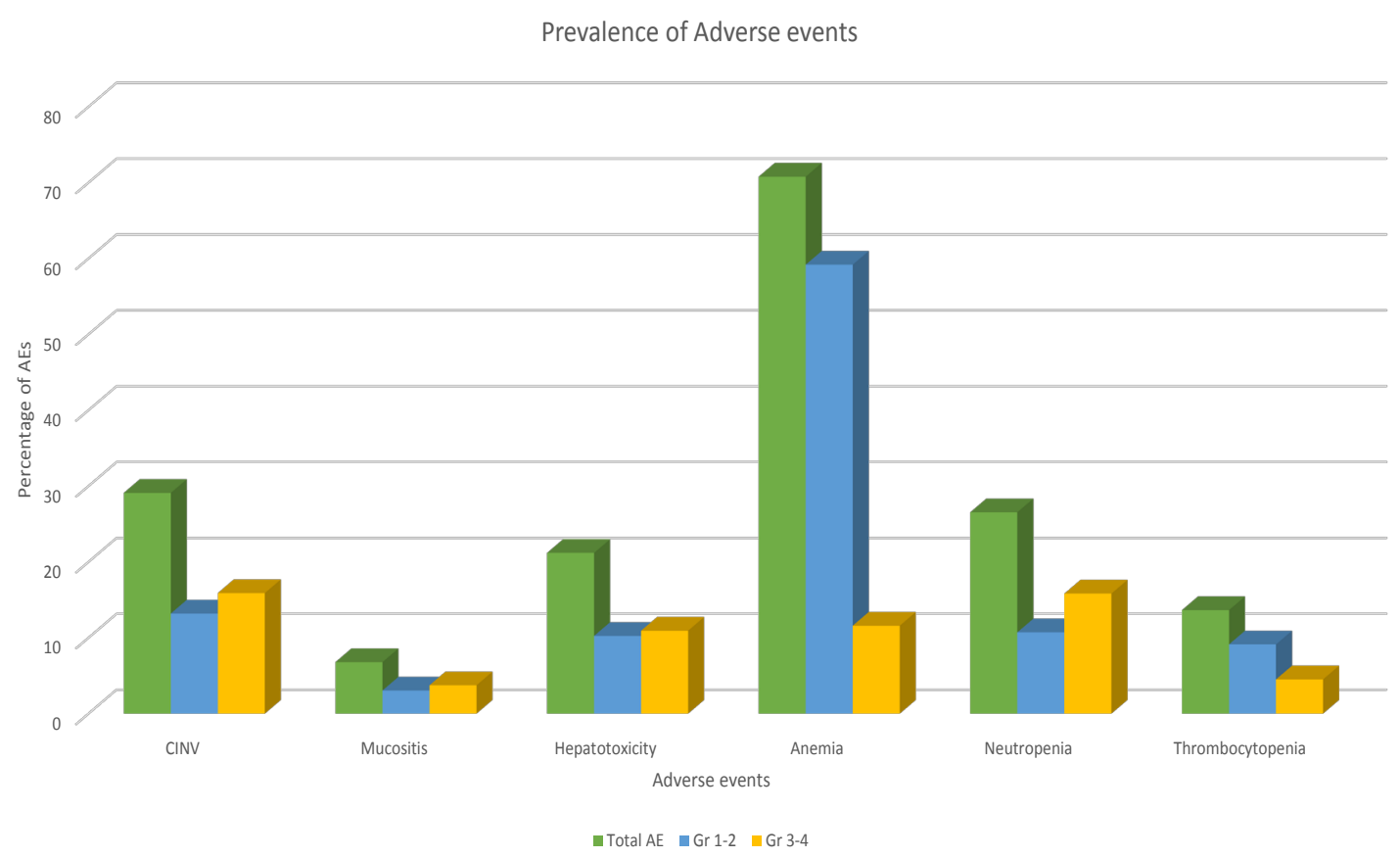

Figure 1. Prevalence of Adverse events. AE, Adverse event; CINV, Chemotherapy induced nausea and vomiting; GR, Grade 
Table 3. Results of Univariable Analysis for Risk Factors Associated with Adverse Events

\begin{tabular}{|c|c|c|c|c|c|c|c|c|}
\hline \multirow[t]{2}{*}{ Factors } & \multicolumn{2}{|c|}{ Hepatotoxicity } & \multicolumn{2}{|c|}{ Anemia } & \multicolumn{2}{|c|}{ Neutropenia } & \multicolumn{2}{|c|}{ Thrombocytopenia } \\
\hline & OR & $95 \% \mathrm{CI}$ & OR & $95 \% \mathrm{CI}$ & OR & $95 \% \mathrm{CI}$ & OR & $95 \% \mathrm{CI}$ \\
\hline \multicolumn{9}{|l|}{ Age } \\
\hline$\leq 10$ years & 1 & reference & 1 & reference & 1 & reference & 1 & reference \\
\hline$>10$ years & 1.01 & 0.94-1.09 & 0.99 & $0.89-1.09$ & 1.01 & $0.96-1.04$ & 0.99 & 0.89-1.09 \\
\hline \multicolumn{9}{|l|}{ Sex } \\
\hline Male & 1 & reference & 1 & reference & 1 & reference & 1 & reference \\
\hline Female & 0.92 & $0.85-0.98$ & 1.04 & $0.95-1.14$ & 0.99 & $0.95-1.03$ & 0.99 & $0.96-1.03$ \\
\hline \multicolumn{9}{|l|}{ Body mass index } \\
\hline Normal & 1 & reference & 1 & reference & 1 & reference & 1 & reference \\
\hline Underweight & 0.97 & $0.88-1.07$ & 0.98 & $0.88-1.09$ & 1.01 & $0.98-1.10$ & 0.98 & $0.88-1.09$ \\
\hline \multicolumn{9}{|c|}{ Cumulative dose of cisplatin } \\
\hline$<300 \mathrm{mg} / \mathrm{m}^{2}$ & 1 & reference & 1 & reference & 1 & reference & 1 & reference \\
\hline$\geq 300 \mathrm{mg} / \mathrm{m}^{2}$ & 1.32 & $1.19-1.44$ & 1.07 & $0.97-1.17$ & 0.97 & $0.95-1.00$ & 1.04 & $0.99-1.02$ \\
\hline \multicolumn{9}{|c|}{ Cumulative dose of ifosfamide } \\
\hline$<60 \mathrm{~g} / \mathrm{m}^{2}$ & 1 & reference & 1 & reference & 1 & reference & 1 & reference \\
\hline$\geq 60 \mathrm{~g} / \mathrm{m}^{2}$ & 0.87 & $0.75-0.99$ & 1.03 & $0.93-1.14$ & 1.04 & $0.97-1.06$ & 0.97 & $0.91-1.03$ \\
\hline \multicolumn{9}{|c|}{ Dose of methotrexate } \\
\hline$<12 \mathrm{~g} / \mathrm{m}^{2}$ & 1 & reference & 1 & reference & 1 & reference & 1 & reference \\
\hline$\geq 12 \mathrm{~g} / \mathrm{m}^{2}$ & 1.58 & $1.56-1.60$ & 1.15 & $1.02-1.29$ & 0.98 & $0.94-1.03$ & 1.07 & $1.03-1.11$ \\
\hline \multicolumn{9}{|c|}{ Methotrexate level at 72 hours } \\
\hline$\leq 0.1 \mu \mathrm{g} / \mathrm{L}$ & 1 & reference & 1 & reference & 1 & reference & 1 & reference \\
\hline$>0.1 \mu \mathrm{g} / \mathrm{L}$ & 1.58 & $1.51-1.68$ & 0.95 & $0.93-0.99$ & 0.9 & $0.88-0.93$ & 0.97 & $0.94-0.98$ \\
\hline \multicolumn{9}{|l|}{ Pre-hydration rate } \\
\hline$>125 \mathrm{~mL} / \mathrm{m}^{2} / \mathrm{h}$ & 1 & reference & 1 & reference & 1 & reference & 1 & reference \\
\hline$\leq 125 \mathrm{~mL} / \mathrm{m}^{2} / \mathrm{h}$ & 1.15 & $1.13-1.15$ & 1.04 & $1.01-1.08$ & 1.14 & $1.09-1.18$ & 1.1 & $1.02-1.05$ \\
\hline
\end{tabular}

$\mathrm{CI}$, confidence interval; OR, odds ratio

chemistries as follows: hypokalemia (K $2.9 \mathrm{mEq} / \mathrm{L})$, hypomagnesemia (Mg $1 \mathrm{mEq} / \mathrm{L})$, hypophosphatemia (phosphate- $3 \mathrm{mEq} / \mathrm{L}$ ), and metabolic acidosis (bicarbonate $18 \mathrm{mEq} / \mathrm{L}$ ). Urinalysis showed proteinuria and glucosuria which was consistent with Fanconi's syndrome. The probability of ifosfamide-induced Fanconi's syndrome in this patient was assessed by the Naranjo Adverse Drug Reaction Probability Scale and classified as probable (Naranjo et al., 1981).

A rare neurological AE, encephalopathy, were also reported in three patients. The first patient, a 14-year-old girl diagnosed with osteosarcoma with lung metastasis receiving IV MTX $12 \mathrm{~g} / \mathrm{m}^{2}$ at week 13 of the treatment course. Seven days after MTX was administered, the patient experienced alteration of consciousness with drowsiness, speechlessness, and seizures. Laboratory results showed normal serum electrolytes ( $\mathrm{Na} 138$ $\mathrm{mEq} / \mathrm{L}, \mathrm{K} 4.4 \mathrm{mEq} / \mathrm{L}, \mathrm{Ca} 8.3 \mathrm{mEq} / \mathrm{L}, \mathrm{Mg} 1.5 \mathrm{mEq} / \mathrm{L}$, and phosphate- $4.4 \mathrm{mEq} / \mathrm{L}$ ) and normal renal function. A brain CT showed no evidence of gross brain parenchymal lesion, intracranial hemorrhage, or venous sinus thrombosis. Subsequently, the patient's serum MTX concentration was taken and got supratherapeutic (2.3 $\mu \mathrm{M})$. The patient was symptomatically treated at the physician's discretion with $10 \mathrm{mg}$ diazepam, and $5 \mathrm{mg}$ of folic acid administered orally. Her clinical condition improved within 2 days after symptomatic treatment. The MTX-induced encephalopathy probability was assessed by the Naranjo Adverse Drug Reaction Probability Scale and classified as probable (Naranjo et al., 1981). Hence, her encephalopathy was probably related to supratherapeutic MTX serum concentration.

The second patient, a 12-year-old female diagnosed with metastatic osteosarcoma being treated with IV MTX $9.6 \mathrm{~g} / \mathrm{m}^{2}$ at week 24 of the treatment course. Two days following MTX administration, the patient developed seizures and alteration of consciousness. Blood biochemistry results were within normal limit including $\mathrm{Na} 134 \mathrm{mEq} / \mathrm{L}, \mathrm{K} 3.9 \mathrm{mEq} / \mathrm{L}, \mathrm{Cl} 93 \mathrm{mEq} / \mathrm{L}, \mathrm{Ca} 10 \mathrm{mEq} / \mathrm{L}$, $\mathrm{Mg} 2 \mathrm{mEq} / \mathrm{L}$, phosphate- $4.3 \mathrm{mEq} / \mathrm{L}$, blood urea nitrogen (BUN) $8.3 \mathrm{mg} / \mathrm{dL}$, and serum creatinine $(\mathrm{sCr}) 0.3 \mathrm{mg} / \mathrm{dL}$. A brain CT scan revealed no evidence of brain gross focal lesions or abnormal leptomeningeal enhancement. Her serum MTX concentration level obtained was $0.19 \mu \mathrm{M}$ at 48 hours and $0.04 \mu \mathrm{M}$ at 58 hours which was consistent with delayed MTX clearance (Inaba et al., 2008). This patient was symptomatically treated with one dose of $2 \mathrm{mg}$ intramuscular vitamin B complex and $5 \mathrm{mg}$ folic acid administered orally. She recovered after 2 days of supportive treatment. The MTX-induced encephalopathy probability was assessed by the Naranjo Adverse Drug Reaction Probability Scale and classified as probable 
DOI: 10.31557/APJCP.2022.23.1.93

Predictors of Chemotherapy Induced Adverse Events in Pediatric Osteosarcoma Patients

Table 4. Results of Multivariable Analysis for Risk Factors Associated with Adverse Events

\begin{tabular}{|c|c|c|c|c|c|c|c|c|}
\hline \multirow[t]{2}{*}{ Factors } & \multicolumn{2}{|c|}{ Hepatotoxicity } & \multicolumn{2}{|c|}{ Anemia } & \multicolumn{2}{|c|}{ Neutropenia } & \multicolumn{2}{|c|}{ Thrombocytopenia } \\
\hline & OR & $95 \% \mathrm{CI}$ & OR & $95 \% \mathrm{CI}$ & OR & $95 \% \mathrm{CI}$ & OR & $95 \% \mathrm{CI}$ \\
\hline \multicolumn{9}{|c|}{ Cumulative dose of cisplatin } \\
\hline$<300 \mathrm{mg} / \mathrm{m}^{2}$ & 1 & reference & 1 & reference & 1 & reference & 1 & reference \\
\hline$\geq 300 \mathrm{mg} / \mathrm{m}^{2}$ & 0.97 & $0.9-1.04$ & 1.02 & $0.78-1.31$ & 0.98 & $0.85-1.15$ & 1.36 & $1.29-1.33$ \\
\hline \multicolumn{9}{|c|}{ Cumulative dose of ifosfamide } \\
\hline$<60 \mathrm{~g} / \mathrm{m}^{2}$ & 1 & reference & 1 & reference & 1 & reference & 1 & reference \\
\hline$\geq 60 \mathrm{~g} / \mathrm{m}^{2}$ & 0.98 & $0.8-1.09$ & 1.12 & $0.89-1.40$ & 0.96 & $0.84-1.09$ & 1.37 & $1.28-1.45$ \\
\hline \multicolumn{9}{|c|}{ Dose of methotrexate } \\
\hline$<12 \mathrm{~g} / \mathrm{m}^{2}$ & 1 & reference & 1 & reference & 1 & reference & 1 & reference \\
\hline$\geq 12 \mathrm{~g} / \mathrm{m}^{2}$ & 1.3 & $1.22-1.39$ & 1.14 & $0.89-1.46$ & 1.9 & $1.34-2.70$ & 1.11 & $1.03-1.18$ \\
\hline \multicolumn{9}{|c|}{ Methotrexate level at 72 hours } \\
\hline$\leq 0.1 \mu \mathrm{g} / \mathrm{L}$ & 1 & reference & 1 & reference & 1 & reference & 1 & reference \\
\hline$>0.1 \mu \mathrm{g} / \mathrm{L}$ & 1.22 & $1.19-1.25$ & 1.75 & $1.12-2.75$ & 3.32 & $1.47-7.49$ & 2.15 & $1.72-2.69$ \\
\hline \multicolumn{9}{|l|}{ Pre-hydration rate } \\
\hline$>125 \mathrm{~mL} / \mathrm{m}^{2} / \mathrm{h}$ & 1 & reference & 1 & reference & 1 & reference & 1 & reference \\
\hline$\leq 125 \mathrm{~mL} / \mathrm{m}^{2} / \mathrm{h}$ & 1.1 & $1.07-1.12$ & 1.03 & $1.01-1.05$ & 1.12 & $1.07-1.17$ & 1.07 & $1.04-1.10$ \\
\hline
\end{tabular}

CI, confidence interval; OR, odds ratio

(Naranjo et al., 1981). Therefore, encephalopathy in this patient was also probably related to MTX therapy.

The third patient, a 13-year-old girl diagnosed with osteosarcoma of the proximal humerus being treated with intravenous ifosfamide $2.65 \mathrm{~g} / \mathrm{m}^{2}$ for three consecutive days. Following the first treatment day, the patient developed alteration of consciousness, drowsiness and seizures. The laboratory results were normal $(\mathrm{Na} 139$ $\mathrm{mEq} / \mathrm{L}, \mathrm{K} 3.5 \mathrm{mEq} / \mathrm{L}, \mathrm{Cl} 104 \mathrm{mEq} / \mathrm{L}, \mathrm{Ca} 10.1 \mathrm{mEq} / \mathrm{L}$, $\mathrm{Mg} 2.1 \mathrm{mEq} / \mathrm{L}$, phosphate- $4.4 \mathrm{mEq} / \mathrm{L}, \mathrm{BUN} 7.1 \mathrm{mg} / \mathrm{dL}$, and $\mathrm{sCr} 0.5 \mathrm{mg} / \mathrm{dL}$ ). A brain $\mathrm{CT}$ revealed no gross focal lesion evidence or abnormal leptomeningeal enhancement in the brain. A loading dose of $800 \mathrm{mg}$ IV phenytoin was administered to control her seizure. Her symptoms were improved 2 days after discontinuing ifosfamide. The probability of ifosfamide-induced encephalopathy in this patient was probable per the Naranjo Adverse Drug Reaction Probability Scale (Naranjo et al., 1981). Thus, encephalopathy in this patient was probably related to ifosfamide treatment.

Subsequently, an univariable and multiple variable analysis to investigate association between risk factors and $\mathrm{AE}$ were performed as shown in Tables 3 and 4 . The results revealed that MTX doses greater than or equal to $12 \mathrm{~g} / \mathrm{m}^{2}$, delayed MTX clearance greater than or equal to 72 hours, and pre-hydration rates of less than or equal to $125 \mathrm{~mL} / \mathrm{m}^{2} / \mathrm{h}$ significantly increased risks of hepatotoxicity and hematologic toxicities. In addition, a cumulative dose of cisplatin greater than or equal to $300 \mathrm{mg} / \mathrm{m}^{2}$ (OR 1.36; 95\% CI 1.29-1.33; $\mathrm{P}=0.023$ ) and a cumulative dose of ifosfamide greater than or equal to $60 \mathrm{~g} / \mathrm{m}^{2}$ (OR 1.37; $95 \%$ CI 1.28-1.45; $\mathrm{P}=0.033)$ significantly increased the risk of thrombocytopenia

\section{Discussion}

In pediatric osteosarcoma, the standard chemotherapy regimen consists of cisplatin, doxorubicin, MTX, and ifosfamide administered as combination therapy (Jain and Kapoor, 2016). In this study, the prevalence of GI toxicities, including CINV, was $29.2 \%$, whereas the prevalence of hepatotoxicity and mucositis was $21.2 \%$ and $6.80 \%$, respectively. These prevalence rates of AE are consistent with previous reports (Traivaree et al., 2018; $\mathrm{Xu}$ et al., 2014), particularly CINV, hepatotoxicity, and mucositis that were observed in $28 \%, 23 \%$, and $8.7 \%$ of patients, respectively. Interestingly, the prevalence of anemia in this study was much higher than that of early report by Marina et al. (Marina et al., 2016) (70.69\% vs $10 \%$ ). The disagreement observed could have been due to a misclassification bias, as thalassemia patients were not excluded from this study. In addition, the prevalence of neutropenia, febrile neutropenia, and thrombocytopenia prevalence $(26.65 \%, 1.73 \%$, and $13.65 \%$, respectively) were much lower than that of Marina et al (94\%, 50\%, and $93 \%$ respectively). Since the use of granulocyte colony-stimulating factor as primary prophylaxis was recommended in pediatric osteosarcoma according to the TPOG protocol, this might have explained the lower incidence of hematologic toxicity in the study setting.

For the association analysis, GEE was chosen to analyze response correlation. GEE is an extension of the generalized linear model for statistical hypothesis testing, which determines the influence of factors on repeated measures of dependent variables comprising binary outcomes that are collected from subjects over time (Hu et al., 1998; Odueyungbo et al., 2008; Stillman, 2003; Ballinger, 2004). To confront with intra-cluster correlation, the covariance matrix is adjusted for estimating parameters by GEE. GEE robustness is another advantage that generated good estimates of the regression parameters (Zorn, 2001).

In the univariable analysis, there was no correlation between age, sex, body mass index, and AEs. In the 
multivariable analysis, risk factors associated with hepatotoxicity and hematologic toxicities included MTX doses greater than or equal to $12 \mathrm{~g} / \mathrm{m}^{2}$, pre-hydration rates less than or equal to $125 \mathrm{~mL} / \mathrm{m}^{2} / \mathrm{h}$, and delayed MTX clearance ( $\geq 72$ hours). These results agree with the observations from Özdemir et al (2016) and Lin et al (2009) wherein MTX doses greater than $3 \mathrm{~g} / \mathrm{m}^{2}$ and delayed MTX clearance ( $\geq 48$ hours) increased risks of both hepatotoxicity and hematologic toxicities. Furthermore, aggressive pre-hydration rates able to reduce the frequency of AE was also reported by Relling et al (1994) and Karremann et al (2014). Hence, the study findings implied that patients undergoing osteosarcoma treatment should be treated with crystalloid fluid hydration at pre-hydration rates of more than $125 \mathrm{~mL} / \mathrm{m}^{2} / \mathrm{h}$. Apart from factors described above, higher cumulative doses of cisplatin and ifosfamide appeared to associate with thrombocytopenia. These results were consistent with the two studies conducted by Fan et al (2015) and Tamamyan et al (2016) reporting an increased thrombocytopenia risk (relative risk [RR] 1.92, 95\% CI 1.23-3.01; $\mathrm{P}=0.004$ ) with ifosfamide-based regimens, previous treatment exposure to cisplatin and MTX.

The standard chemotherapy in osteosarcoma could have also induced nephrotoxicity predominantly in patients who received cumulative cisplatin doses greater than or equal to $300 \mathrm{mg} / \mathrm{m}^{2}$ and cumulative ifosfamide doses greater than or equal to $60 \mathrm{~g} / \mathrm{m}^{2}$ (Perazella, 2012). The prevalence of acute kidney injury and electrolyte imbalance (hypomagnesemia and hypokalemia) in this study were $1.37 \%$ and $1.67 \%$, respectively, as similarly observed in previous report (Oberlin et al., 2009). Rarely, Fanconi's syndrome could have been observed in patients receiving cumulative ifosfamide doses greater than or equal to $90 \mathrm{~g} / \mathrm{m}^{2}$ (Ho et al., 1995; Skinner et al., 2000). Likewise, Langer et al (2004) reported a 1\% prevalence of Fanconi's syndrome in patients who were treated with higher cumulative doses of cisplatin and ifosfamide (Aleksa et al., 2001; Ruggiero et al. 2017) Concordance with the study Fanconi's syndrome was observed and risk factors associated with Fanconi's syndrome in the study might have been related to history of previous treatments with cumulative cisplatin doses greater than or equal to $360 \mathrm{mg} / \mathrm{m}^{2}$ and HD-MTX (Hall et al.,2014; Oberlin et al., 2009).

According to the three cases above, encephalopathy was observed. A hypothetically related to MTX-induced encephalopathy (Inaba et al., 2008; Vezmar et al., 2003; Rubnitz et al., 1998) possibly relates to a substantially increased homocysteine level, leading to oxidative stress and neuronal death. In contrast, ifosfamide could have induced encephalopathy through its toxic metabolite chloroacetaldehyde (Ajithkumar et al., 2007). Symptoms normally occur within 2-96 hours after ifosfamide administration. From the encephalopathy case series described in this study, the plausible risk factors being MTX dose $\geq 12 \mathrm{~g} / \mathrm{m}^{2}$ and delayed MTX clearance were in accordance with previous reports as encephalopathy was observe among patients aged greater than 10 years, receiving higher doses of MTX $\left(\geq 8 \mathrm{~g} / \mathrm{m}^{2}\right)$, and possessed a delayed MTX clearance ( $\geq 42$ hours) (Bhojwani et al.,
2014; Dufourg et al., 2007; Inaba et al., 2008; Rubnitz et al., 1998).

In terms of ifosfamide-induced encephalopathy, the possible risk factors according to the case described in this study might have been related to prior nephrotoxic agents exposure such as history of platinum-based treatment which was consistent with several observations (David and Picus, 2005; Tajino et al., 2010).

This is foremost the largest study to identify the prevalence of chemotherapy-induced AE in pediatric patients with osteosarcoma in Thailand. This research was conducted at a large-scale tertiary care medical center, thereby contributing to a larger sample size than previously reported studies. Our results might have some clinical implications in optimizing pediatric osteosarcoma toxicity management. The pre-hydration rates $>125$ $\mathrm{mL} / \mathrm{m}^{2} / \mathrm{h}$ should be maintained in patients undergoing systemic treatment of osteosarcoma to prevent major AE. Therapeutic drug monitoring should be performed in with high HD-MTX and delayed MTX clearance.

There are some limitations as a cross-sectional design is not ideal to describe a causal relationship between drugs and AEs, and might have led to an underestimation of the prevalence of rare AEs (Levin, 2006; Kesmodel, 2018; Flanelly and Jankowski, 2014). Nevertheless, the study results confirmed magnitudes and distributions of association between risk factors, including MTX doses $\geq 12 \mathrm{~g} / \mathrm{m}^{2}$, delayed MTX clearance ( $\geq 72$ hours), and prehydration rates of less than or equal to $125 \mathrm{~mL} / \mathrm{m}^{2} / \mathrm{h}$ as previously reported in a cohort study (Puts et al., 2014).

The administration of chemotherapy in pediatric patients with osteosarcoma led to the major AE, including GI and hematologic toxicities. The prevalence of adverse outcomes was higher in the studied risk group. The results of this study have potential implications for the prevention and monitoring of AE in pediatric patients with osteosarcoma who receive chemotherapy in Thailand.

\section{Author Contribution Statement}

Conceptualization, P.S., P.K. and S.S.; methodology, P.S., P.K. and S.S.; formal analysis, P.S. and S.S.; data curation, P.S., J.Y. and S.S.; writing-original draft preparation, P.S., P.K., J.Y., M.S., S.C. and S.S.; writingreview and editing, P.S., P.K., J.Y., M.S., S.C. and S.S. All authors have read and agreed to the published version of the manuscript.

\section{Acknowledgments}

We would like to thank all the healthcare providers who participated in this study for providing valuable information and support to our research.

\section{Funding Statement}

This work was supported by the Faculty of Pharmaceutical Sciences, Khon Kaen University, Thailand.

\section{Conflict of interest}

The authors declare no conflict of interest 


\section{Institutional Review Board Statemen}

The study was conducted according to guidelines of the Declaration of Helsinki and approved by the Center for Ethics in Human Research, Khon Kaen University, Khon Kaen, Thailand (HE621309).

\section{Informed Consent Statement}

Patient consent was waived due to the retrospective study design by the Center for Ethics in Human Research, Khon Kaen University, Khon Kaen, Thailand.

\section{Availability of data}

No additional data were generated in the study.

\section{References}

Ajithkumar T, Parkinson C, Shamshad F, Murray P (2007). Ifosfamide encephalopathy. Clin Oncol, 19, 108-14.

Aleksa K, Woodland C, Koren G (2001). Young age and the risk for ifosfamide induced nephrotoxicity: a critical review of two opposing studies. Pediatr Nephrol, 16, 1153-8.

Ballinger GA (2004). Using generalized estimating equations for longitudinal data analysis. Organ Res Methods, 7, 127-50.

Bhojwani D, Sabin ND, Pei D, et al (2014). Methotrexateinduced neurotoxicity and leukoencephalopathy in childhood acute lymphoblastic leukemia. J Clin Oncol, 32, 949-59.

Constable EC, Daniels MA, Drew MG, et al (2021). Common terminology criteria for adverse events (CTCAE) version 5. https://ctep.cancer.gov/protocolDevelopment/electronic applications/ctc.htm\#ctc_50, (accessed 31 March 2019).

David KA, Picus J (2005). Evaluating risk factors for the development of ifosfamide encephalopathy. Am J Clin Oncol, 28, 277-80.

Dufourg MN, Landman-Parker J, Auclerc MF, et al (2007). Age and high-dose methotrexate are associated to clinical acute encephalopathy in FRALLE 93 trial for acute lymphoblastic leukemia in children. Leukemia, 21, 238-47.

Fan XL, Cai GP, Zhu LL, Ding GM (2015). Efficacy and safety of ifosfamide-based chemotherapy for osteosarcoma: a metaanalysis. Drug Des Devel Ther, 9, 5925-32.

Flannelly KJ, Jankowski KR (2014). Research designs and making causal inferences from health care studies. J Health Care Chaplain, 20, 25-38.

Geenen MM, Cardous-Ubbink MC, Kremer LC, et al (2007). Medical assessment of adverse health outcomes in long-term survivors of childhood cancer. JAMA, 297, 24, 2705-15.

Gianferante DM, Mirabello L, Savage SA (2017). Germline and somatic genetics of osteosarcoma-connecting aetiology, biology and therapy. Nat Rev. Endocrinology, 13, 480-91.

Hall AM, Bass P, RJ. Unwin (2014). Drug-induced renal Fanconi syndrome. QJM, 107, 261-9.

Hanafy E, Al Jabri A, Gadelkarim G, (2018). Tumor histopathological response to neoadjuvant chemotherapy in childhood solid malignancies: is it still impressive. $\mathrm{J}$ Invest Med. 66, 289-97.

Ho PT, Zimmerman K, Wexler L.H, (1995). A prospective evaluation of ifosfamide-related nephrotoxicity in children and young adults. Cancer, 76, 2557-64.

Hu FB, Goldberg J, Hedeker D, Flay B.R, Pentz MA (1998). Comparison of population-averaged and subject-specific approaches for analyzing repeated binary outcomes. Am J Epidemiol, 147, 694-703.

Inaba H, Khan RB, Laningham FH, et al (2008). Clinical and radiological characteristics of methotrexate-induced acute encephalopathy in pediatric patients with cancer. Ann Oncol, $19,178-84$
Jackson TM, Bittman M, Granowetter L (2016). Pediatric Malignant Bone Tumors: A Review and Update on Current Challenges, and Emerging Drug Targets, Curr Probl Pediatr Adolesc Health Care, 46, 213-28.

Jain S, Kapoor G (2016). Chemotherapy in osteosarcoma: current strategies. J Bone Soft Tissue Tumors, 2, 27-32.

Janeway KA, Grier HE (2010). Sequelae of osteosarcoma medical therapy: a review of rare acute toxicities and late effects. The Lancet Oncology, 11, 670-8.

Karremann M, Sauerbier J, Meier C, et al (2014). The impact of prehydration on the clearance and toxicity of high-dose methotrexate for pediatric patients. Leuk Lymphoma, 55(12), 2874-8

Kesmodel US (2018). Cross-sectional studies - what are they good for. Acta Obstet Gynecol Scand, 97, 388-93.

Ksontini F, Guermazi F, Khadija M, et al (2018). Descriptive epidemiology of malignant primary osteosarcoma in Tunisia 1980-2016. Asian Pac J Cancer Care, 3(4), 81-6.

Langer T, Stöhr W, Bielack S, et al (2004). Late effects surveillance system for sarcoma patients. Pediatr Blood Cancer, 42, 373-9.

Levin KA (2006). Study design III: Cross-sectional studies. Evid Based Dent. 7, 24-5.

Lin F, Juan Y, Zheng SE, et al (2009). Relationship of serum methotrexate concentration in high-dose methotrexate chemotherapy to prognosis and tolerability: A prospective cohort study in Chinese adults with osteosarcoma. Curr Ther Res Clin Exp 70, 150-60.

Marina NM, Smeland S, Bielack SS, et al (2016). Comparison of MAPIE versus MAP in patients with a poor response to preoperative chemotherapy for newly diagnosed high-grade osteosarcoma (EURAMOS-1): an open-label, international, randomised controlled trial. Lancet Oncol, 17, 1396-408.

Misaghi A., Goldin A., Awad M, Kulidjian A.A (2018). Osteosarcoma: a comprehensive review. SICOT-J, 4.

Naranjo CA, Busto U, Sellers EM, (1981). A method for estimating the probability of adverse drug reactions. CPT, 30, 239-45.

Noah F, Van Dyne E.A, Bernthal N (2016). Malignant bone tumors, in: Lanzkowsky's Manual of Pediatric Hematology and Oncology Eds P. Lanzkowsky, J.M. Lipton, J.D. Fish. Elsevier Inc., London, pp. 524-43.

Oberlin O, Fawaz O, Rey A, et al (2009). Long-term evaluation of Ifosfamide-related nephrotoxicity in children, J Clin Oncol 27, 5350-5355.

Odueyungbo A, Browne D, Akhtar-Danesh N, Thabane L (2008). Comparison of generalized estimating equations and quadratic inference functions using data from the National Longitudinal Survey of Children and Youth (NLSCY) database. BMC Med Res Methodol, 8, 28.

Özdemir ZC, Bozkurt Turhan A, Düzenli Kar Y, Bör Ö (2016). The frequency of hepatotoxicity and myelotoxicity in leukemic children with different high doses of methotrexate. Int J Pediatr Adolesc Med, 3, 162-8.

Perazella M. A (2012). Onco-nephrology: renal toxicities of chemotherapeutic agents. Clin J Am Soc Nephrol, 7, 1713-1721.

Puts MTE, Tu HA, Tourangeau A, et al (2014). Factors influencing adherence to cancer treatment in older adults with cancer: a systematic review. Ann Oncol. 25, 564-77.

Relling MV, Fairclough D, Ayers D, et al (1994). Patient characteristics associated with high-risk methotrexate concentrations and toxicity. J Clin Oncol, 12, 1667-72.

Rubnitz JE, Relling MV, Harrison PL (1998). Transient encephalopathy following high-dose methotrexate treatment in childhood acute lymphoblastic leukemia. Leukemia 12, 1176-81. 
Ruggiero A, Ferrara P, Attina G, Rizzo D, Riccardi R (2017). Renal toxicity and chemotherapy in children with cancer. Br J Clin Pharmacol 83, 2605-14.

Skinner R, Cotterill SJ, Stevens M (2000). Risk factors for nephrotoxicity after ifosfamide treatment in children: a UKCCSG late effect group study. Br J Cancer 82(10), 1636-45.

Stillman S (2003). Review of generalized estimating equations by Hardin and Hilbe. SJ, 3, 208-10.

Tajino T, Kikuchi S, Yamada H, Takeda A, Konno S (2010). Ifosfamide encephalopathy associated with chemotherapy for musculoskeletal sarcomas: incidence, severity, and risk factors. J Orthop Sci, 15, 104-11.

Tamamyan G, Danielyan S, Lambert MP (2016). Chemotherapy induced thrombocytopenia in pediatric oncology. Crit Rev Oncol Hematol. 99, 299-307.

The Thai Pediatric Oncology Group: ThaiPOG, National protocol for the treatment childhood cancer 2016. http://www.si.mahidol.ac.th/th/department/pediatrics/ pdf/service/Guideline/HematologyandOncology/ Nationalprotocoltreatmentofcancer.pdf, (accessed 1 November 2018).

Traivaree C, Likasitthananon N, Monsereenusorn C, Rujkijyanont P (2018). The effect of intravenous hydration strategy on plasma methotrexate clearance during intravenous high-dose methotrexate administration in pediatric oncology patients. Cancer Manag. Res. 10, 4471-78.

Vezmar S, Becker A, Bode U, Jaehde U (2003). Biochemical and clinical aspects of methotrexate neurotoxicity. Chemotherapy 49, 92-104.

Wiangnon S, Veerakul G, Nuchprayoon I, et al (2011). Childhood cancer incidence and survival 2003-2005, Thailand: study from the Thai Pediatric Oncology Group, Asian Pac J Cancer Prev, 12, 2215-20.

Xu M, Xu SF, Yu XC (2014). Clinical analysis of osteosarcoma patients treated with high-dose methotrexate-free neoadjuvant chemotherapy. Curr Oncol, 21, e678-e84.

Zorn CJ (2001). Generalized estimating equation models for correlated data: a review with applications. Am J Pol Sci, 45, 470-90.

This work is licensed under a Creative Commons AttributionNon Commercial 4.0 International License. 